\title{
Genetic deletion of osteopontin in TRAMP mice skews prostate carcinogenesis from adenocarcinoma to aggressive human-like neuroendocrine cancers
}

\author{
Giorgio Mauri ${ }^{1}$, Elena Jachetti ${ }^{1}$, Barbara Comuzzi ${ }^{1}$, Matteo Dugo ${ }^{2}$, Ivano Arioli ${ }^{1}$, \\ Silvia Miotti ${ }^{1}$, Sabina Sangaletti ${ }^{1}$, Emma Di Carlo ${ }^{3,4}$, Claudio Tripodo ${ }^{5}$, Mario P. \\ Colombo ${ }^{1}$ \\ ${ }^{1}$ Molecular Immunology Unit, Department of Experimental Oncology and Molecular Medicine, Fondazione IRCCS Istituto \\ Nazionale Tumori, 20133, Milano, Italy \\ ${ }^{2}$ Functional Genomics and Bioinformatics, Department of Experimental Oncology and Molecular Medicine, Fondazione IRCCS \\ Istituto Nazionale Tumori, 20133, Milano, Italy \\ ${ }^{3}$ Department of Medicine and Science of Aging, Section of Anatomic Pathology and Molecular Medicine, "G. d'Annunzio" \\ University, 66100, Chieti, Italy \\ ${ }^{4}$ Ce.S.I. Aging Research Center, "G. d'Annunzio" University Foundation, 66100, Chieti, Italy \\ ${ }^{5}$ Tumor Immunology Unit, Department of Health Sciences, University of Palermo, 90127, Palermo, Italy \\ Correspondence to: Mario P. Colombo, e-mail: mariopaolo.colombo@istitutotumori.mi.it
}

Keywords: prostate cancer, extracellular matrix, osteopontin, neuroendocrine

Received: November 18, $2015 \quad$ Accepted: November 23, 2015

Published: December 19, 2015

\section{ABSTRACT}

Osteopontin (OPN) is a secreted glycoprotein, that belongs to the non-structural extracellular matrix (ECM), and its over expression in human prostate cancer has been associated with disease progression, androgen independence and metastatic ability. Nevertheless, the pathophysiology of OPN in prostate tumorigenesis has never been studied. We crossed TRansgenic Adenocarcinoma of the Mouse Prostate (TRAMP) mice with OPN deficient (OPN ${ }^{-1-}$ ) mice and followed tumor onset and progression in these double mutants. Ultrasound examination detected the early onset of a rapidly growing, homogeneous and spherical tumor in about $60 \%$ of OPN ${ }^{-1-}$ TRAMP mice. Such neoplasms seldom occurred in parental TRAMP mice otherwise prone to adenocarcinomas and were characterized for being androgen receptor negative, highly proliferative and endowed with neuroendocrine (NE) features. Gene expression profiling showed up-regulation of genes involved in tumor progression, cell cycle and neuronal differentiation in OPN-deficient versus wild type TRAMP tumors. Downregulated genes included key genes of TGF $\beta$ pathway, including SMAD 3 and Filamin, which were confirmed at the protein level. Furthermore, NE genes and particularly those characterizing early prostatic lesions of OPN-deficient mice were found to correlate with those of human prostate NE tumours. These data underscore a novel role of OPN in the early stages of prostate cancer growth, protecting against the development of aggressive NE tumors.

\section{INTRODUCTION}

Prostate carcinoma (PCa) is one of the most common tumors in developed countries and the second leading cause of cancer-related death in the USA [1]. PCa is a multifocal disease, which progresses from high-grade prostate intraepithelial neoplasia (PIN). Initially, the tumor responds to therapies that mainly consist in androgen ablation, but it eventually becomes androgen resistant due to alterations in androgen receptor expression or related signalling. The main drivers of $\mathrm{PCa}$ development and progression are still unknown and effective therapies for the androgen-resistant stage are not yet available.

Stromal microenvironment modifications occurring at the stage of precancerous PIN lesions are no longer considered bystanders. In this context, SIBLINGs (Small Integrin-Binding Ligand N-Linked Glycoproteins), a family of non-structural extracellular matrix (ECM) 
proteins, seem to favor tumor progression by hijacking their physiological functions in wound healing and tissue remodeling [2].

Osteopontin (OPN) is a secreted protein, belonging to SIBLINGs, present in body fluids and almost ubiquitous in tissues. OPN contributes to tissue homeostasis through the regulation of stem cell pools within specific niches [3]. OPN over-expression in human PCa has been associated with disease progression towards androgen independence and metastasis $[4,5]$. Therefore, at the late stages of $\mathrm{PCa}$ OPN targeted inactivation might be a promising strategy. However, the role of OPN at onset of PCa has not been investigated so far. To address this issue, we crossed OPN deficient $\left(\mathrm{OPN}^{-/}\right)$mice with the TRansgenic Adenocarcinoma of the Mouse Prostate (TRAMP) mice, which carry the SV40 large T antigen (Tag) under the control of the rat probasin regulatory element, selectively activated by androgens in the prostate epithelia. TRAMP mice invariantly develop PIN (8-16 weeks) that progresses to focal invasive adenocarcinoma (16-20 weeks) and then to moderately differentiated ( 24 weeks) and poorly differentiated (24-30 weeks) adenocarcinoma [6, 7].

Although the reported over-expression of OPN in advanced disease let envisage tumor reduction in $\mathrm{OPN}^{-/}$TRAMP mice, we unexpectedly observed the early onset of highly proliferative, anaplastic androgenindependent tumors, characterized by a neuroendocrine (NE) phenotype. The corresponding human NE carcinoma characterized by aggressive behaviour, poor response to standard treatments and dismal prognosis $[8,9]$ accounts for nearly $10 \%$ of cases and seldom occurs in relatively young patients. Notably, areas of NE differentiation occur in advanced PCa patients after androgen ablation therapy $[10,11]$. Five to ten percent of TRAMP mice spontaneously develop tumors with the NE phenotype. The mechanisms driving their onset in OPN deficiency are here investigated [12].

\section{RESULTS}

\section{OPN deletion enhances anaplastic tumor development in TRAMP mice}

We followed tumor onset and progression in OPN $^{-1-}$ TRAMP $(n=14)$ and TRAMP $(n=16)$ mice between 12 and 30 weeks (wks) of age by ultrasound (US) echographic examination. US allows evaluating prostate morphology and dimensions, and the elastomeric response to the echographic probe pressure, highlighting density alterations. The scan performed in 3D mode allows inspection of every prostatic lobe for the presence of tumor before it becomes palpable. US and histologic analyses of the prostate revealed no differences between the two strains until mice were 15 wks old. Between 18 and 22 wks of age a large, well-defined spheroid tumor appeared in $\mathrm{OPN}^{-/}$TRAMP (Figure $1 \mathrm{~A}$ and $1 \mathrm{~B}$ ) but not in age-matched TRAMP mice (Figure 1A). These spheroid tumors were even larger than the heterogeneous and multifocal tumors, also infiltrating the seminal vesicles, that characterize $30 \mathrm{wks}$ old TRAMP mice (Figure 1A). Such growth differences were confirmed by weighting the genitourinary organs after necropsy at 30 wks of age or following mice survival (Figure 1C).

Histopathological analysis was performed on cohorts of mice sacrificed at different time points (18 to 20 wks, 20 to $30 \mathrm{wks},>30 \mathrm{wks}$ ). Anaplastic lesions (Figure $1 \mathrm{D}$, right) were present in roughly $60 \%$ of $\mathrm{OPN}^{-/-}$TRAMP mice in all cohorts, but only in few TRAMP mice and only after the 20th week of age (Table 1). Conversely, multifocal adenocarcinoma lesions (Figure 1D, left) were present in the majority of TRAMP mice at all time points (Table 1). As expected, positivity for OPN was found in both epithelial and stromal cells in TRAMP prostates (Figure 1E).

To compare the anaplastic lesions from the two strains, tumors were collected at $30 \mathrm{wks}$ of age for histopathology and immunohistochemistry. At this age, both strains develop poorly differentiated lesions. However, tumors formed in OPN ${ }^{-/}$TRAMP mice were characterized by marked anaplasia and higher expression of Ki67, N-cadherin and laminin (Figure 2).

These data suggest that the lack of OPN at the beginning of the transformation process skews the nascent tumor towards a more aggressive, undifferentiated phenotype.

\section{Absence of OPN promotes androgen- independent tumor growth in the early stages of prostate carcinogenesis}

Androgen receptor was expressed by normal and transformed glandular prostatic tissue of TRAMP mice (Figure 3A) as well as by normal epithelial cells of $\mathrm{OPN}^{-/}$TRAMP prostates, but not by tumors of $\mathrm{OPN}^{-1}$ TRAMP mice (Figure 3B). This finding suggested that in $\mathrm{OPN}^{-/}$TRAMP mice tumors could rise as androgen independent.

Androgen ablation is a standard treatment for patients with advanced PCa (www.cancer.gov/types/ prostate/hp/prostate-treatment-pdq\#section/all).

Unfortunately these patients frequently develop androgen resistance and ineffective treatment options remain. This setting can be modeled in TRAMP mice by castration [13]. We investigated whether the lack of OPN affects mice susceptibility to hormone withdrawal in early phases of tumor development. TRAMP and $\mathrm{OPN}^{-/}$TRAMP mice (both $n=11$ ) were castrated before sexual maturation (6 wks) and tumor growth was monitored by US examination. Among castrated TRAMP mice, 9 showed prostate involution, 1 developed adenocarcinoma and the remaining one developed an anaplastic spheroid tumor with incidence similar to that of non-castrated TRAMP 
mice (12\%; Figure 3C). Castrated OPN ${ }^{-/}$TRAMP mice did not develop any evident adenocarcinoma, whereas 8 showed anaplastic tumors $(73 \%$, versus $60 \%$ of non- castrated littermates). Prostate involution occurred in the remaining $3(27 \%)$ castrated mice (Figure 3C). Castration after sexual maturation (12 wks) did not change the
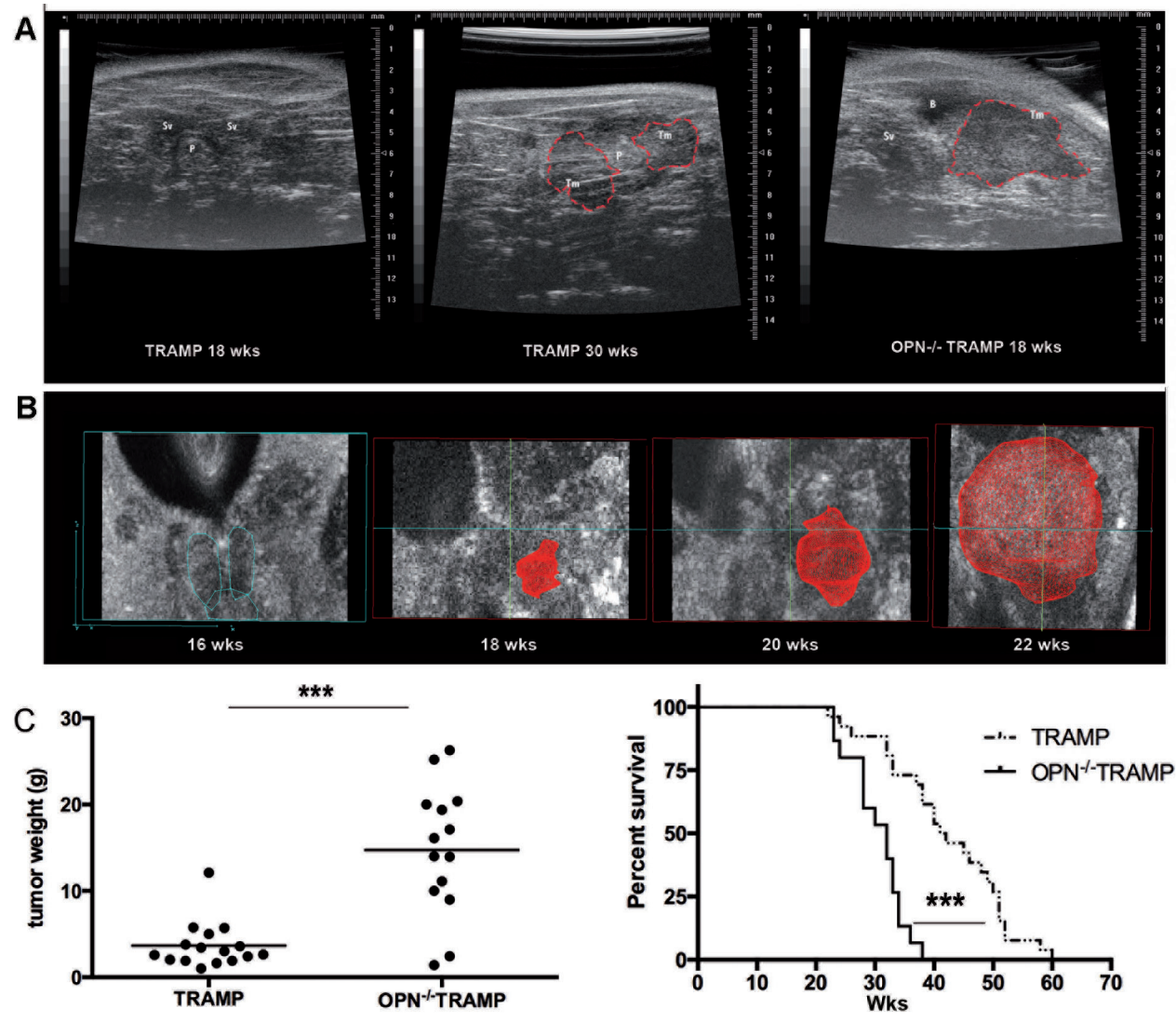

D
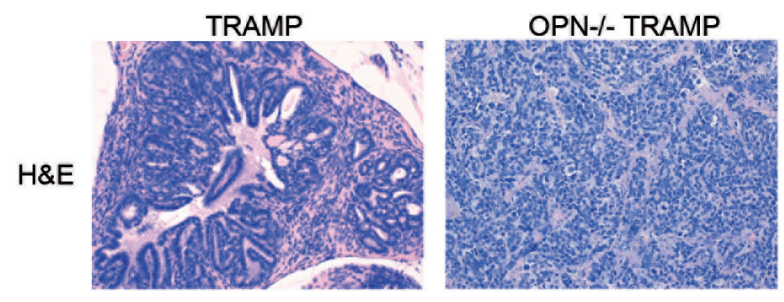

$\mathrm{E}$

TRAMP

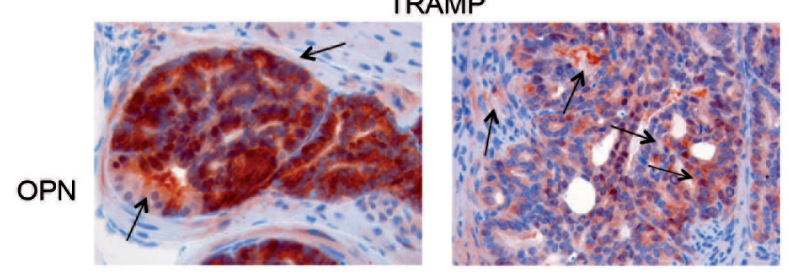

Figure 1: $\mathrm{OPN}^{-/-}$TRAMP mice develop anaplastic tumors with increased frequency. A. TRAMP and OPN ${ }^{-/-}$TRAMP mice ( $n=16$ and 14, respectively) were followed for tumor growth by echographic ultrasound examination. Representative echographic abdominal imaging of prostate of $18 \mathrm{wks}$ (left) and 30wks old TRAMP (center) or 18 wks old OPN ${ }^{-/}$TRAMP (right) mice are reported. Red dashed lines outline tumor mass. Scale bars at the borders are in millimeters. B. 3D rendering of echographic images of prostatic tumor growth (outlined in red) in a OPN ${ }^{--}$TRAMP mouse at 16, 20, 22 wks. C. Left: Mice followed echographically as described in (a) were euthanized at 30 wks of age. Graph reports weight of genitourinary apparatus of TRAMP $(n=16)$ and OPN ${ }^{-/}$TRAMP $(n=14)$ as indicator of tumor burden (Student's $T$ test: ***: $p<0.0001)$. Right: Alternatively, two other cohorts of TRAMP $(n=26)$ and OPN ${ }^{-/-}$TRAMP $(n$ $=15$ ) mice were followed for survival; graph depicts Kaplan-Meier survival curve (Log Rank test: ***: $p<0.0001)$. D. Representative H\&E staining of adenocarcinoma developing in $30 \mathrm{wks}$ old TRAMP mice or anaplastic tumors grown in $18 \mathrm{wks}^{\mathrm{old}}$ OPN $\mathrm{TRAMP}^{-/} \mathrm{Tice}$. Magnification x200. At least 3 mice per group/age were analyzed and one representative picture is reported. E. Representative OPN staining in adenocarcinoma samples developing in 30 wks old TRAMP mice. Magnification x400. Arrows highlight positive cells. At least 3 mice per group/age were analyzed and one representative picture is reported. 
Table 1: Percentage of mutifocal or anaplastic lesions detected by histology in prostates of TRAMP or OPN-/- TRAMP mice at the indicated time points

\begin{tabular}{|c|c|c|c|c|c|c|}
\hline & \multicolumn{2}{|c|}{$\begin{array}{c}18<\text { wks }<20(n=7 \text { TRAMP } \\
n=7 \text { OPN-/-TRAMP })\end{array}$} & \multicolumn{2}{|c|}{$\begin{array}{c}20<w k s<30(n=15 \text { TRAMP } \\
n=15 \text { OPN-/-TRAMP })\end{array}$} & \multicolumn{2}{|c|}{$\begin{array}{c}=30 \mathrm{wks}(n=16 \text { TRAMP; } n=14 \\
\text { OPN-/-TRAMP) }\end{array}$} \\
\hline & $\begin{array}{l}\text { Multifocal } \\
\text { lesions }\end{array}$ & $\begin{array}{c}\text { Anaplastic } \\
\text { lesions }\end{array}$ & $\begin{array}{l}\text { Multifocal } \\
\text { lesions }\end{array}$ & $\begin{array}{l}\text { Anaplastic } \\
\text { lesions }\end{array}$ & $\begin{array}{l}\text { Multifocal } \\
\text { lesions }\end{array}$ & $\begin{array}{c}\text { Anaplastic } \\
\text { lesions }\end{array}$ \\
\hline TRAMP & $100 \%$ & $0 \%$ & $78 \%$ & $22 \%$ & $93 \%$ & $7 \%$ \\
\hline $\begin{array}{l}\text { OPN -/- } \\
\text { TRAMP }\end{array}$ & $50 \%$ & $50 \%$ & $40 \%$ & $60 \%$ & $46 \%$ & $54 \%$ \\
\hline
\end{tabular}

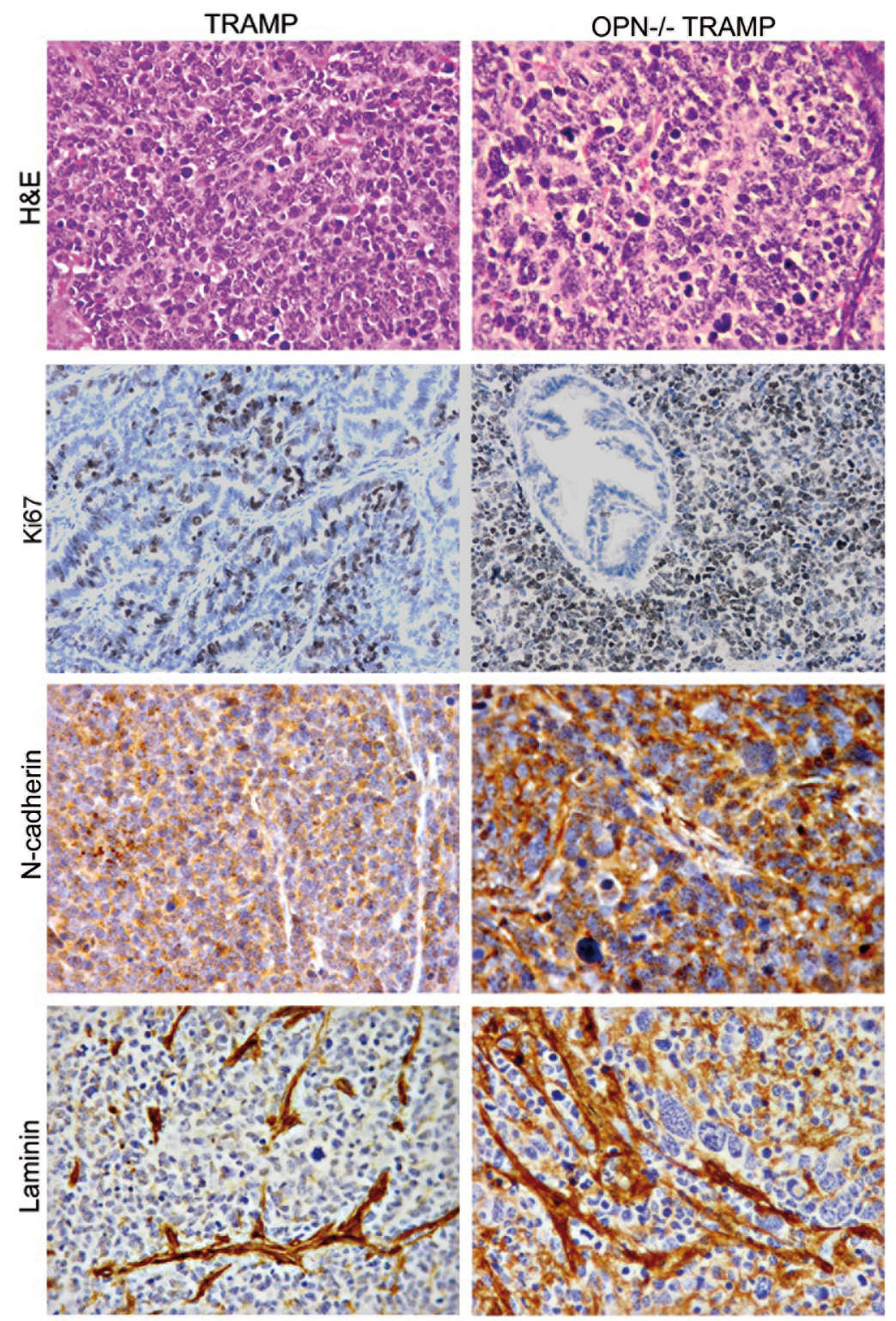

Figure 2: Phenotype of anaplastic lesions developing in TRAMP and OPN ${ }^{-/ T R A M P ~ m i c e . ~ R e p r e s e n t a t i v e ~ h e m a t o x i l i n ~}$ and eosin (H\&E) staining and immunohistochemistry for Ki67, N-cadherin and Laminin of anaplastic tumors developing in 30 wks old TRAMP and $\mathrm{OPN}^{--}$TRAMP mice as indicated. Magnification $\times 400$. At least 3 mice per group were analyzed and one representative picture is reported. 

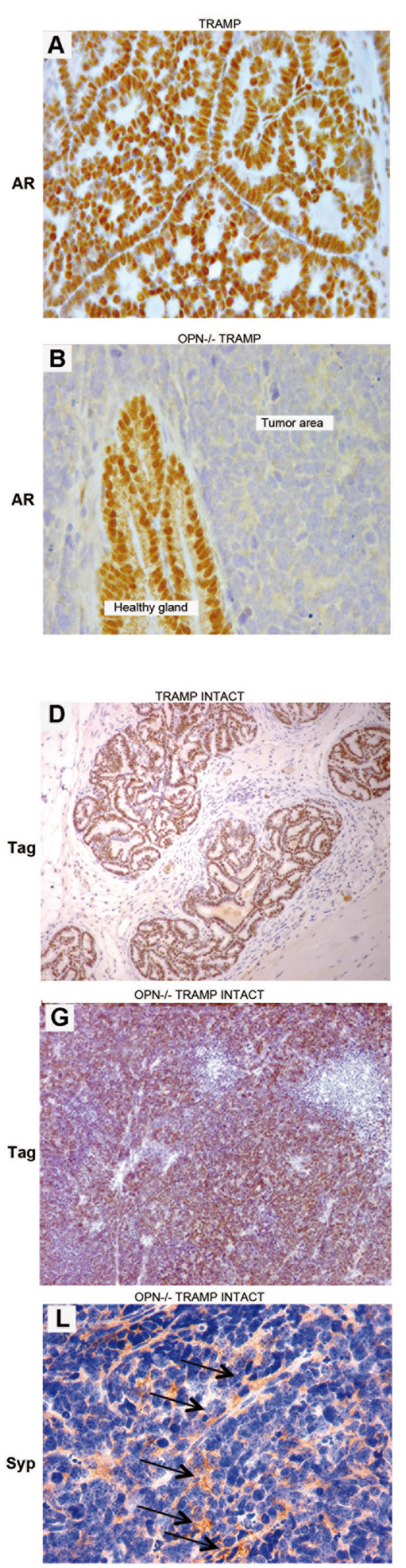

C
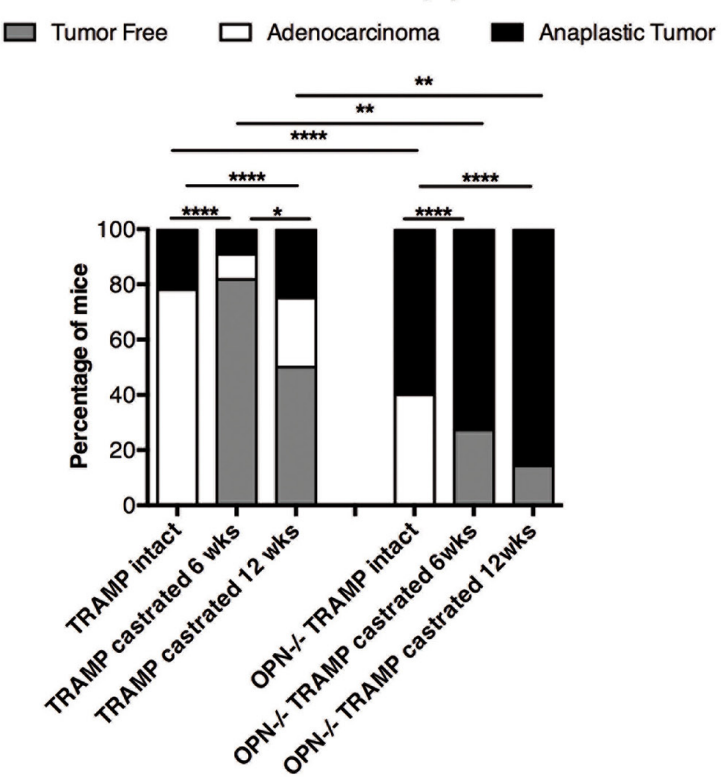

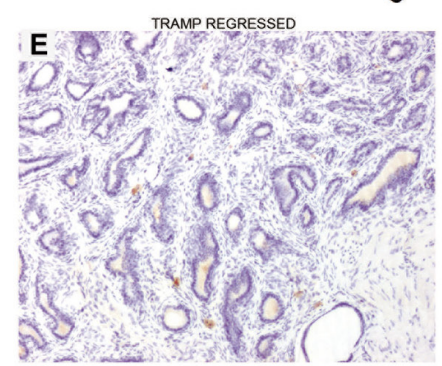

OPN-/-TRAMP TUMOR AFTER CASTRATION 6 wks
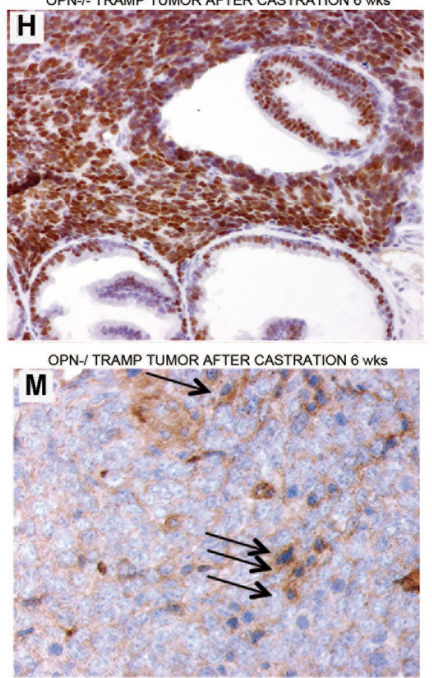
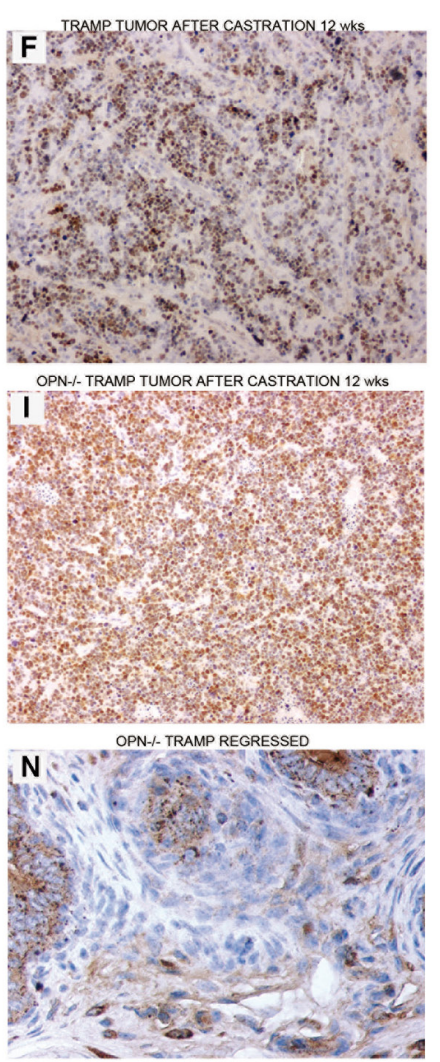

Figure 3: Anaplastic tumors developing in OPN ${ }^{-/}$TRAMP mice are androgen independent and express NE markers. A-B. Representative immunohistochemistry staining of androgen receptor (AR) showing positivity in transformed prostates of 18 wks TRAMP mice (A), and in healthy glands surrounding tumor mass in age-matched $\mathrm{OPN}^{--}$TRAMP mice (B). Tumor areas in $\mathrm{OPN}^{-/-}$TRAMP mice were AR negative (B). Magnification $\mathrm{x} 400$. At least 3 mice per group were analyzed and one representative picture is reported. C. Frequency of prostatic lesions in TRAMP and OPN ${ }^{--}$TRAMP either intact, or castrated at $6(n=11$ for both groups) or 12 wks $(n=4$ and 7, respectively) and sacrificed at 30 wks of age. (Fisher exact test *: $p<0.05 ; * *: p<0.01 ; * * * *: p<0.0001$ ) D-F. Representative Tag staining in prostate of intact TRAMP mice (D), in regressed prostate (E) or in anaplastic tumors (F) emerged in TRAMP mice after being castrated at 12 wks. Magnification x 200. G-I. Representative Tag staining in anaplastic prostate tumors developed in OPN $^{-/}$TRAMP mice either intact (G), castrated at 6 wks (H), or at $12 \mathrm{wks}(\mathrm{I})$. L-N. Representative synaptophisin (Syp) staining in tumors developed in $\mathrm{OPN}^{--}$TRAMP mice either intact (L) or castrated at $6 \mathrm{wks}(\mathrm{M})$ or in $\mathrm{OPN}^{--}$TRAMP mice showing prostate involution after castration $(\mathrm{N})$. Arrows indicate positive cells. Magnification x 200. 
incidence of anaplastic tumors in $\mathrm{OPN}^{-/}$TRAMP mice, but increased up to $25 \%$ the rate of anaplastic tumors in TRAMP mice (Figure 3C) as expected $[13,14]$.

In TRAMP mice the expression of Tag is controlled by the rat Probasin promoter [6] which is regulated by androgens [15]. That means that Tag expression in TRAMP mice reflects androgen responsiveness of epithelial prostate cells. Immunohistochemistry revealed Tag expression by luminal cells of intact tumorigenic prostate glands of TRAMP mice (Figure 3D) but not by cells of involute prostates (Figure 3D). As already seen by others $[13,16]$, Tag expression was maintained in cells of anaplastic lesions occurring in castrated TRAMP mice (Figure 3F). Interestingly, Tag was expressed at high levels on anaplastic tumors of $\mathrm{OPN}^{-/}$TRAMP mice regardless castration (Figure 3G-3I). These results confirmed that the anaplastic tumors arising in $\mathrm{OPN}^{-/-}$TRAMP mice developed as androgen-independent.

Synaptophysin staining confirmed the NE phenotype of anaplastic tumors [12] developed in both non-castrated (Figure 3L) and castrated (Figure $3 \mathrm{M}$ ) $\mathrm{OPN}^{-/}$TRAMP mice. Synaptophysin did not stain the epithelia of $\mathrm{OPN}^{-/-}$TRAMP prostates regressed because of castration (Figure $3 \mathrm{~N}$ ). Therefore, thereafter in this manuscript tumors from $\mathrm{OPN}^{-/}$TRAMP mice will be referred as NE tumors.

To test the possible OPN source either epithelial or hematopoietic that is relevant in this experimental model, bone marrow (BM) transplantation was performed to obtain chimeras lacking or not OPN in the prostatic epithelium or in the radio-resistant stroma cell components. In detail, BM from OPN-competent wild-type (WT) mice was transplanted into $6 \mathrm{wks}$ old $\mathrm{OPN}^{-/}$TRAMP mice as well as BM, either from $\mathrm{OPN}^{-/}$ or WT mice, was transplanted into TRAMP mice. Mice were then sacrificed at $30 \mathrm{wks}$ of age for histopathologic analysis of prostates. NE tumor frequency remained determined by the host genotype regardless that of donor $\mathrm{BM}$, with high incidence in $\mathrm{OPN}^{-/}$TRAMP and low incidence in TRAMP recipient chimeras (Figure S1). These results suggest that OPN produced by the host radio-resistant cell component contrast the occurrence of NE tumors.

\section{Basal origin of tumors in OPN ${ }^{-1-}$ TRAMP mice}

Whether prostatic NE cancers have a distinct cellular origin from adenocarcinomas or rather they originate from the peculiar differentiation of common precursors is still debated. As far as the TRAMP model is concerned, it is believed that NE tumors can arise from a subset of stem/ progenitor cells populating the basal cell layer of glandular ducts $[12,17,18]$. We thus tested the expression of the basal p63, [19-21] and the luminal CK8 [22] markers in association with the cell proliferation marker Ki67.
In prostate lobes of 15 wks old TRAMP mice, clusters of proliferating cells co-expressed $\mathrm{Ki} 67$ and CK8 (Figure 4A) whereas p63 positive cells were Ki67 negative (Figure 4C). On the contrary, in prostates of $\mathrm{OPN}^{-/}$TRAMP mice luminal CK8 cells mostly lacked Ki-67 (Figure 4B), which instead co-localized with p63 in the basal compartment (Figure 4D). Notably, according to previous reports on prostate cancer patients [21], some cytoplasmic staining of p63 was detectable (Figure 4C and 4D) whereas nuclear p63 localization was canonic in normal prostate of wild-type mice (Figure S2).

\section{Gene expression profile confirms the NE phenotype of $\mathrm{OPN}^{-/}$TRAMP tumors}

To obtain a broad view of the transcriptional features distinctive of NE and adenocarcinoma lesions, we compared gene expression profiles of prostate samples collected from 18 weeks old OPN ${ }^{-/}$TRAMP mice bearing macroscopic NE lesions (OPT-tm) with those from 30 wks old TRAMP mice (T30) representative of adenocarcinomas (ADC). A detailed description of samples used from microarray comparison is reported in Suppl. Table 1, and a detailed flow of samples comparison is shown in Suppl. Figure 3

Unsupervised hierarchical clustering clearly distinguished gene expression profiles of TRAMP mice with adenocarcinoma from $\mathrm{OPN}^{-/}$TRAMP mice with NE tumor (Figure S4). We found 2536 differentially expressed genes between the two classes (absolute fold change $\geq 2$ and FDR $<5 \%$; Heatmap in Figure $5 \mathrm{~A}$ ). To identify biological processes distinguishing the two histotypes we performed Gene Set Enrichment Analysis (GSEA) using gene sets compiled from canonical pathway and Gene Ontology databases. Significant gene sets $(\mathrm{FDR}<5 \%, p$-value $<0.001)$ were visualized as interaction networks using the Enrichment map plugin in Cytoscape (Figure S5). NE tumors were characterized by the activation of gene sets involved in cell cycle and proliferation, transcription and RNA-processing, and neural system. These findings were confirmed by functional analysis of the differentially expressed genes using Ingenuity Pathway Analysis (IPA) software. In OPT-tm, among genes involved in cell cycle, E2f2 and Ccne 2 were the most up-regulated, while Ccnd1, whose up-regulation has been reported in TRAMP mice [23, 24], was the most down-regulated. These results were confirmed by RT-qPCR analysis (Figure 5B) and were concordant with the high cellular proliferative rate observed both macroscopically and histologically in $\mathrm{OPN}^{-/-}$TRAMP tumors. The most up-regulated genes in OPT-tm samples were those involved in neurological diseases and in neuronal system development, including L-Dopa Decarboxylase $(D d c$, fold change $=172.2)$ and synaptophisin $(S y p$, fold change $=31.3)$, confirming 
the NE phenotype of anaplastic tumors arising in $\mathrm{OPN}^{-/-}$TRAMP mice. Upregulation at protein level of DDC and SYP in NE tumors was validated by western blot (Figure 5C).

IPA predicted $T g f b 1$ to be an uprstream regulator of the differentially expressed genes in OPT-tm samples $(p=8.93 \mathrm{e}-37)$. Indeed 157 targets of $T g f b 1$ were listed as differentially expressed genes and 84 of them had an expression consistent with Tgfb1 pathway inhibition. This finding was supported by the significant downregulation of $T g f b 1$ in OPT-tm $(F D R=0.005)$, although this gene was excluded from the list of differentially expressed genes because of a fold-change of -1.53 . Moreover, Filamin A (FLNA), a key TGF $\beta$ activator [25], was among the down-regulated genes in our signature and western blot confirmed FLNA protein down regulation (Figure $5 \mathrm{C}$ ).
$T g f b r 2$ and $T g f b r 3$ transcripts were significantly down-regulated in OPT-tm, whereas Tgfbr1, which is responsible for SMADs phosphorylation and activation, was up-regulated. As protein levels of TGFbRI and TGFbRII were comparable between $\mathrm{OPN}^{-/}$TRAMP NE tumors and TRAMP adenocarcinoma (not shown), we focused on proteins downstream the TGF $\beta$ pathway, particularly Smad2 and Smad3, which are crucial mediators of TGF $\beta$ activity in PCa [26]. Smad3 was down-regulated in GEP and in western blot in NE tumors from $\mathrm{OPN}^{-/}$TRAMP mice (Figure 5D). On the contrary, Smad2 transcript and protein, as well as phosphorylation of SMAD3 and SMAD, remained unchanged in $\mathrm{OPN}^{-/}$TRAMP NE tumors versus TRAMP adenocarcinomas (Figure 5D). These results suggested that in absence of OPN the TGF $\beta$ pathway and the cell cycle were down-regulated, likely through the activity of FLNA and SMAD3.

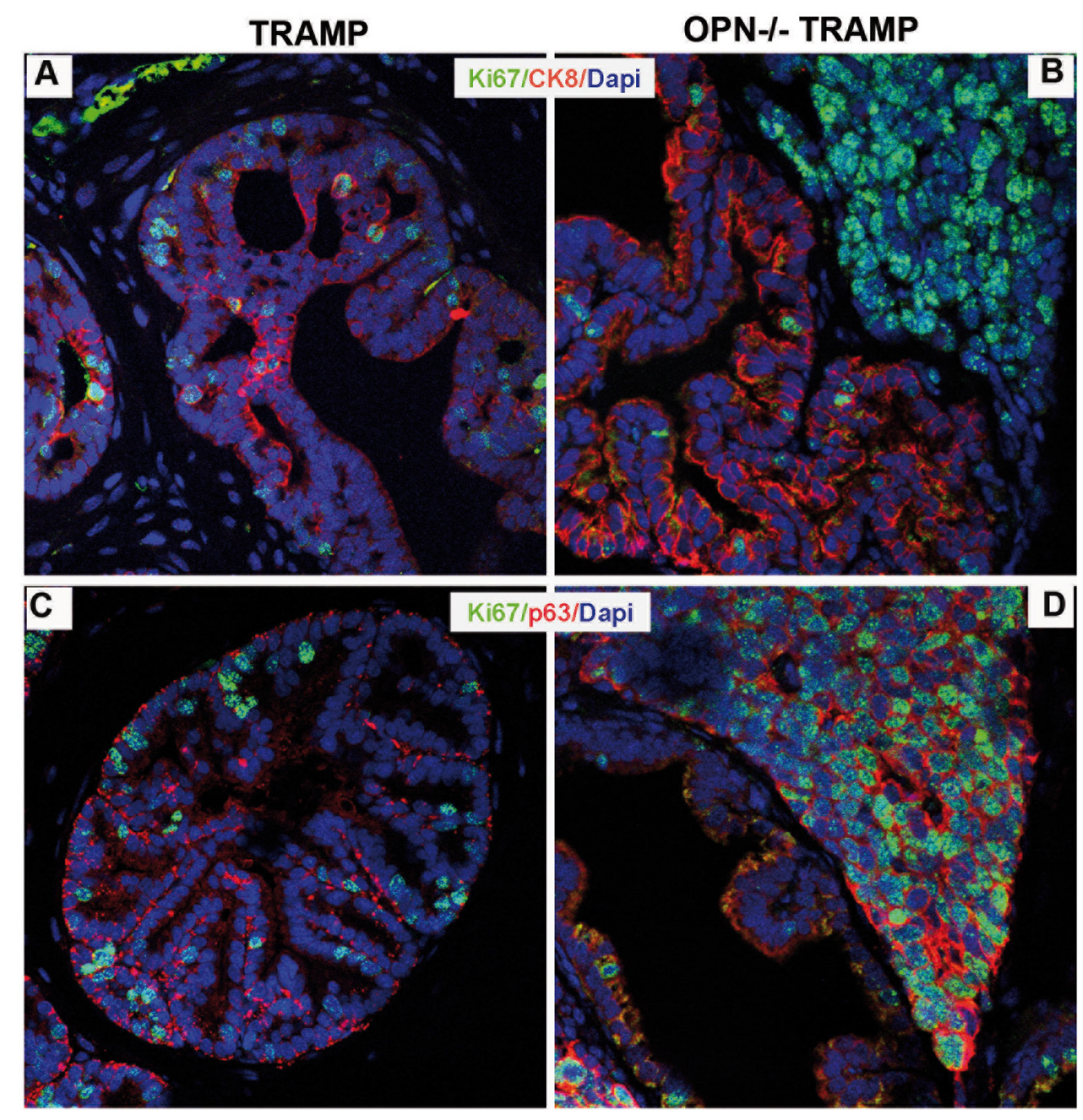

Figure 4: NE tumors of OPN--TRAMP mice have a basal phenotype. A-D. Representative immunofluorescence staining of Ki67 (green) and CK8 (red; panels A and B) and of Ki67 (green) and p63 (red; panels C and D) in prostates of TRAMP and OPN ${ }^{-/-}$TRAMP mice of 15 wks of age. Blue: dapi. White arrows indicate cells co-expressing Ki67 and CK8, while yellow arrows indicate cells co-expressing Ki67 and p63. Three mice per group were analyzed and one representative picture is reported. 

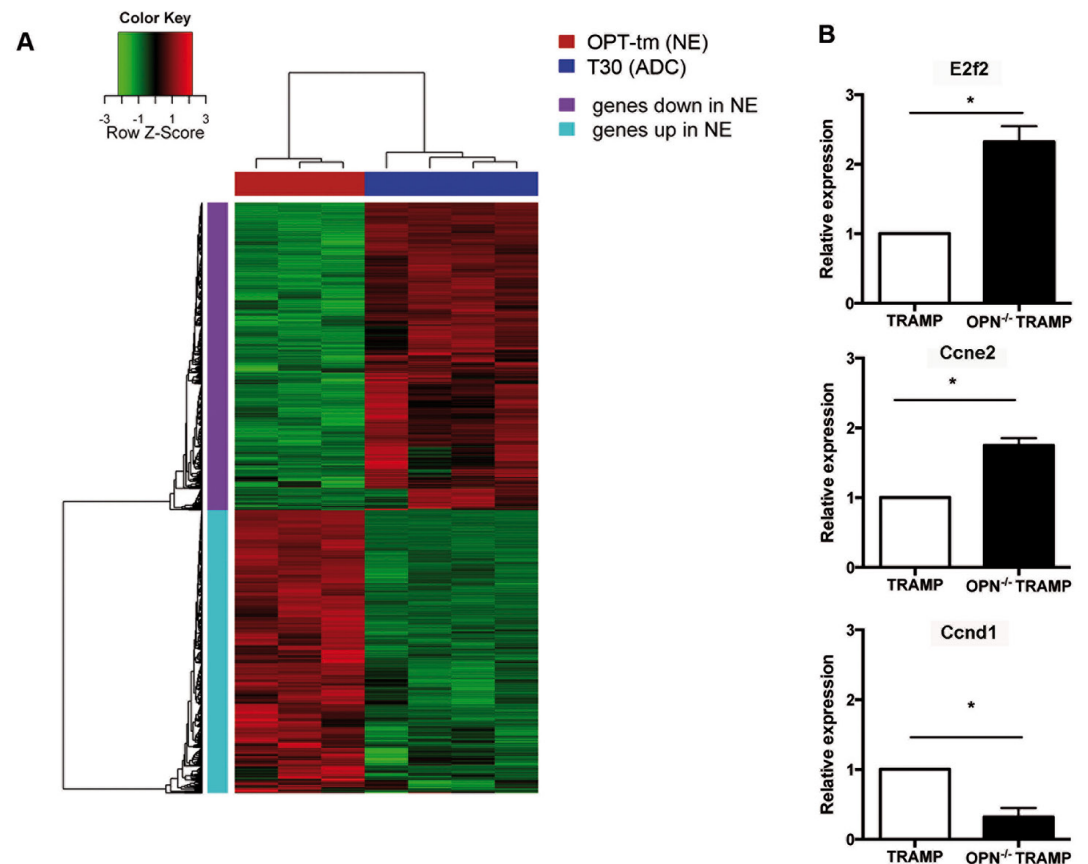

C
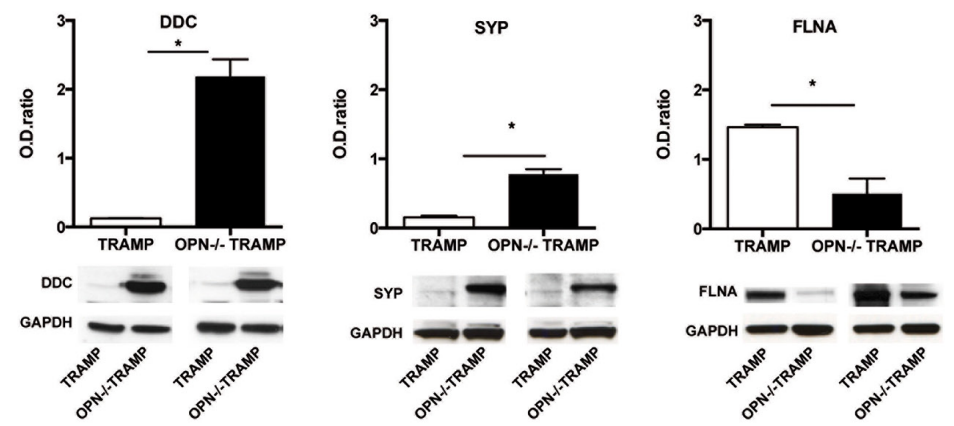

D
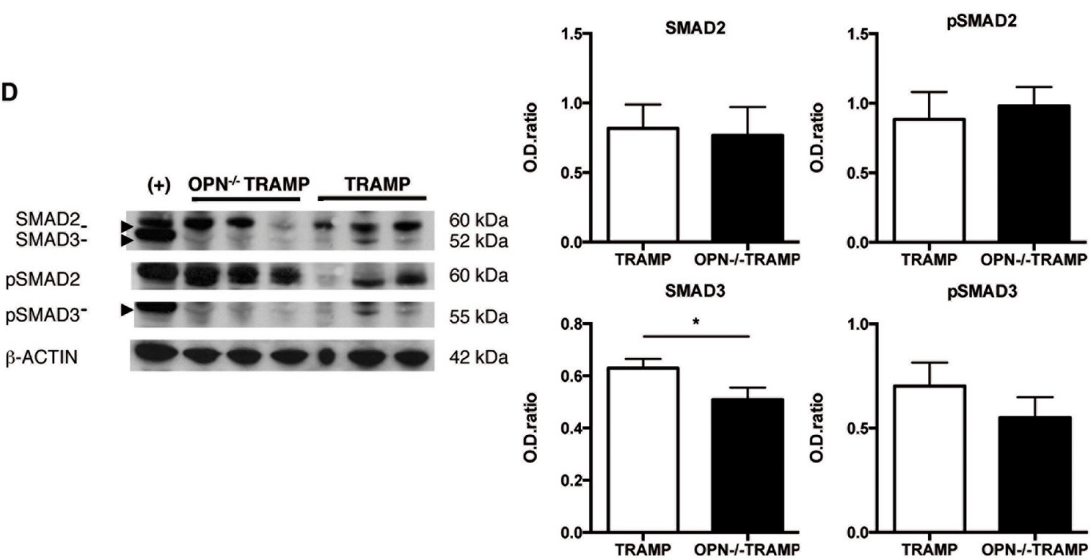

Figure 5: Gene expression profile confirms NE phenotype of OPN ${ }^{-/ T R A M P}$ tumors. A. Heatmap of differentially expressed genes in NE tumors of 18 wks old $\mathrm{OPN}^{-/}$TRAMP (OPT18 tm) vs adenocarcinoma (ADC) of 30 wks old TRAMP (T30) mice. Red and green color indicates relative expression as indicated. Refer to Suppl. Table 1 and Suppl. Figure3 for detailed description of samples analyzed and flow chart of comparisons. B. Relative expression +/- SD of E2f2, Ccne2 and Ccnd1 in prostates of 30 wks TRAMP and 18 wks OPN-/-TRAMP mice as assessed by real-time PCR. Experiment was repeated twice with samples from three different mice per group. C. Western blot analysis for L-Dopa Decarboxylhase (DDC), synaptophysin (SYP) and Filamin (FLNA) in prostates of 30 wks TRAMP and 18 wks OPN-/-TRAMP mice. Values are quantified to internal control (GAPDH). Picture reports cropped blots around the specific bands. Experiment was repeated twice with samples from two different mice per group. D. Western blot analysis for SMAD2, SMAD3 and their phosphorylated forms (pSMAD2 and pSMAD3, respectively) or $\beta$-actin (as control) in prostates of 30 wks TRAMP and 18 wks OPN-/-TRAMP mice. HeLa cells stimulated with TGFb were used as positive control (+). Values are quantified to internal control ( $\beta$-actin). Picture reports cropped blots around the specific bands Experiment was repeated twice with samples from three different mice per group. Student's $T$ test: *: $p<0.0001$. 


\section{$\mathrm{NE}$ signature from early lesions of $\mathrm{OPN}^{-/}$ TRAMP mice is enriched in genes overexpressed in human NE prostate and can predict NE tumor outcome}

We have the idea to test the possibility of defining a gene signature that could predict the onset of NE disease in PCa patients. Using the 2536 genes distinguishing NE from adenocarcinoma prostate tumors, we applied unsupervised hierarchical clustering to gene expression data from prostates of TRAMP mice of 18 wks of age $(\mathrm{T} 18, n=4)$ and from $\mathrm{OPN}^{-/-}$TRAMP mice of 15 $(n=5)$ or $18(n=9)$ wks of age (OPT15 and OPT18, respectively) all devoid of US-detectable lesions (Table S1 and Figure S3 describe samples and class comparisons). We found that early prostate samples fell into two distinct clusters (Figure 6a). The first cluster was composed of 5 samples, hereafter called Early-NE, whose gene expression pattern resembled that of NE OPT-tm. These samples were all from OPN $^{-/}$TRAMP mice (4 of 18 wks old and 1 of $15 \mathrm{wks}$ ), indicating that at the time of sacrifice they were likely bearing a developing NE tumor, well before any possible diagnosis. The second cluster contained 17 samples, hereafter called Early-ADC, whose gene expression profile was similar to that of TRAMP adenocarcinomas. All early samples from TRAMP (T18) and from $\mathrm{OPN}^{--}$TRAMP mice, without NE features, fell into this cluster. To identify early markers specific for NE tumor a comparison between Early-NE and Early$A D C$ GEPs was performed. We found that all the 184 differentially expressed genes (absolute fold change $\geq 2$ and FDR $<5 \%$ ), were upregulated in the Early-NE group (Figure 6A). According to GSEA these genes are involved in cell cycle and nervous system development, but also in down-regulation of pro-inflammatory processes (Figure 6B, Table S2 and S3). This list of 184 genes provides a transcriptional profile distinguishing NE tumors from adenocarcinoma at early stages of transformation.

We were interested in asking whether the transcriptional alterations observed in our mouse models could find correlation with human tumors counterpart. As gene expression datasets containing both $\mathrm{NE}$ and adenocarcinoma human $\mathrm{PCa}$ are not publicly available we used GSEA to test whether genes previously identified as up- or down- regulated in human prostate NE tumors versus prostate adenocarcinomas [27] were positively or negatively enriched in mouse NE lesions. Results showed that genes over-expressed in NE human tumors were also positively enriched in both OPT-tm and Early- $N E$ samples (Figure 6C, left, and Figure 6E, left, respectively). The core enrichment genes, accounting for the gene set's enrichment, were related to cancer, neuronal development, cell growth and cell cycle progression (Figure 6D and 6F, and Table S4 and S5), confirming the results obtained with the murine NE signatures. Conversely, genes downregulated in NE patients were significantly negatively enriched in both OPT-tm and Early-NE samples while up-regulated in T30 (late adenocarcinoma) and Early$A D C$ samples (Figure 6C, right, and Figure 6E, right, respectively). Taken together these results showed that gene expression profiles of tumors arising in $\mathrm{OPN}^{--}$TRAMP mice were similar to those of human NE prostatic cancers.

\section{DISCUSSION}

ECM confers proper architecture and function to tissues. It regulates connections and communication between cells and is responsible for the continued tissue remodeling in development or healing. Of great interest is the role of ECM in cancer, representing a tissue that does not heal [28], especially in premalignant to malignant transition [29].

OPN is an ECM non-structural protein, member of the SIBLINGs, endowed with pro-migratory and proangiogenic properties in transformed tissues [30] and considered a potential tumor marker [31]. In $\mathrm{PCa}$ its expression in primary tumors [4] and bone metastases [32] correlates with poor prognosis and its targeting has been considered a therapeutic option [33].

Despite the numerous studies, none has investigated the role of OPN at onset of PCa. The present work is the first to study the effect of OPN genetic deficiency in TRAMP, a mouse model mimicking human PCa. Considering its high expression in advanced human $\mathrm{PCa}$ we would have expected that OPN knockout in TRAMP mice would have delayed tumor onset or reduced tumor size. To our surprise, $\mathrm{OPN}^{-/}$TRAMP mice displayed early onset and accelerated tumor development in comparison to TRAMP mice. These tumors developed as spherical masses, macroscopically detectable at 18 wks of age by echographic examination. Histopathology classified these tumors as undifferentiated and immunohistochemistry indicated the loss of AR, the retention of Tag and the gaining of synaptophysin. The same characteristics have also been described for NE tumors that seldom develop spontaneously in TRAMP mice unless stimulated by castration [12, 18]. Castration in TRAMP mice has different outcomes depending on the age of mice at surgery. Before sexual maturation it causes prostate involution and prevents neoplastic transformation [13] whereas at late stages it promotes the development of androgen independent NE tumors; which express high levels of Tag $[13,16,34]$. In OPN $^{-1-}$ TRAMP mice castration at either 6 or 12 weeks had no effect on NE tumor development, which still occurred at high rate in an hormone independent way.

We also found that proliferating Ki67 positive cells in prostates of $\mathrm{OPN}^{-/}$TRAMP mice express cytoplasmic p63, thus confirming that the basal prostate compartment is transforming in $\mathrm{OPN}^{-/}$TRAMP mice. This is in line with the hypothesis that NE tumors arise 
A
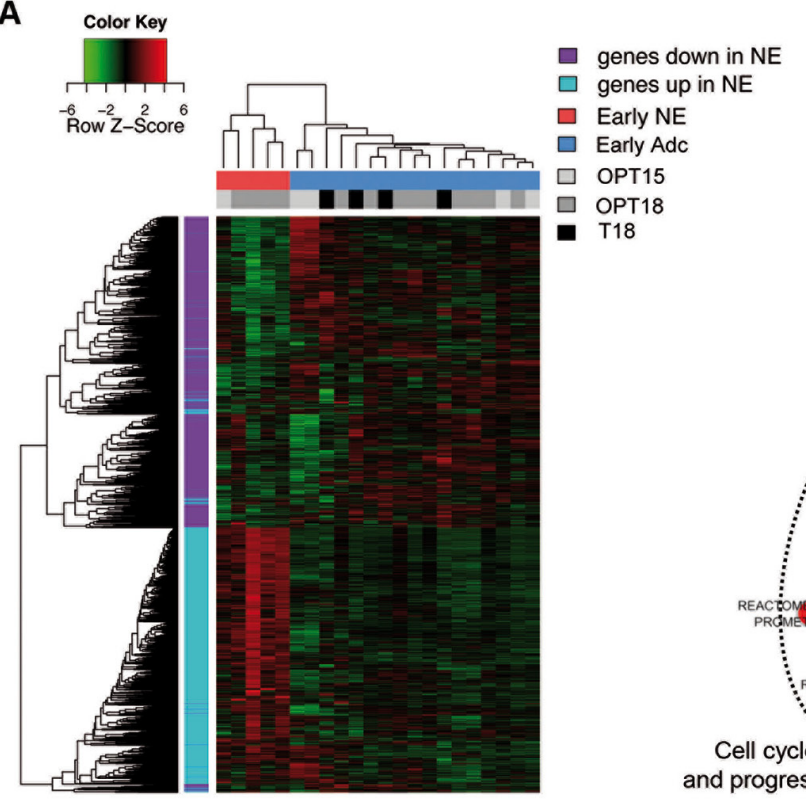

an

$\square$ OPT18

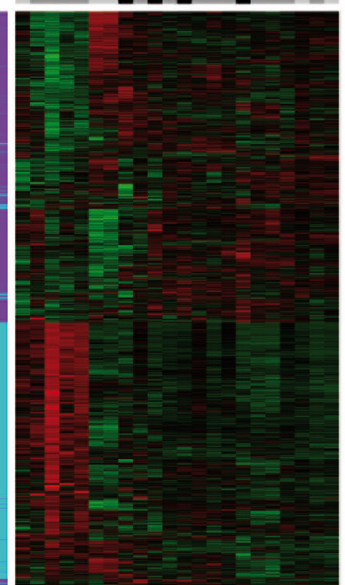

- T18

C

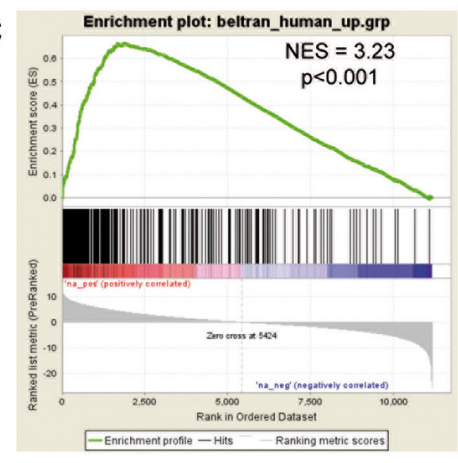

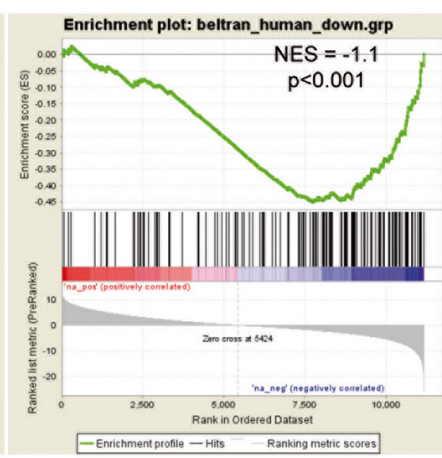

E

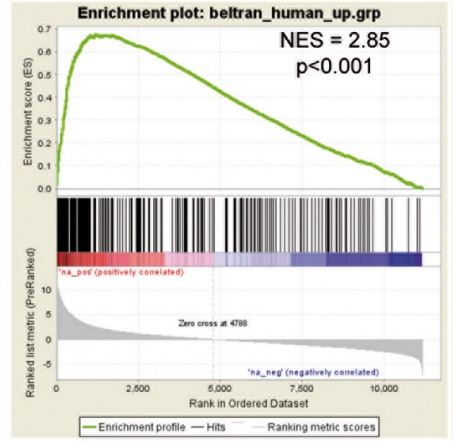

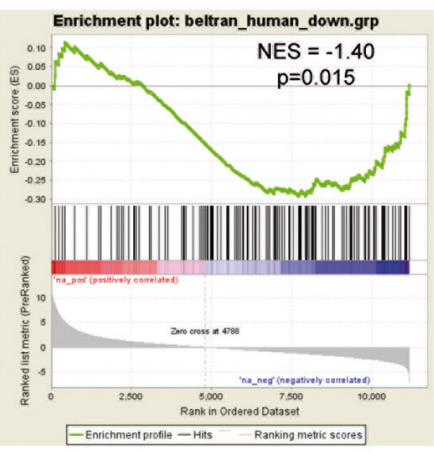

D
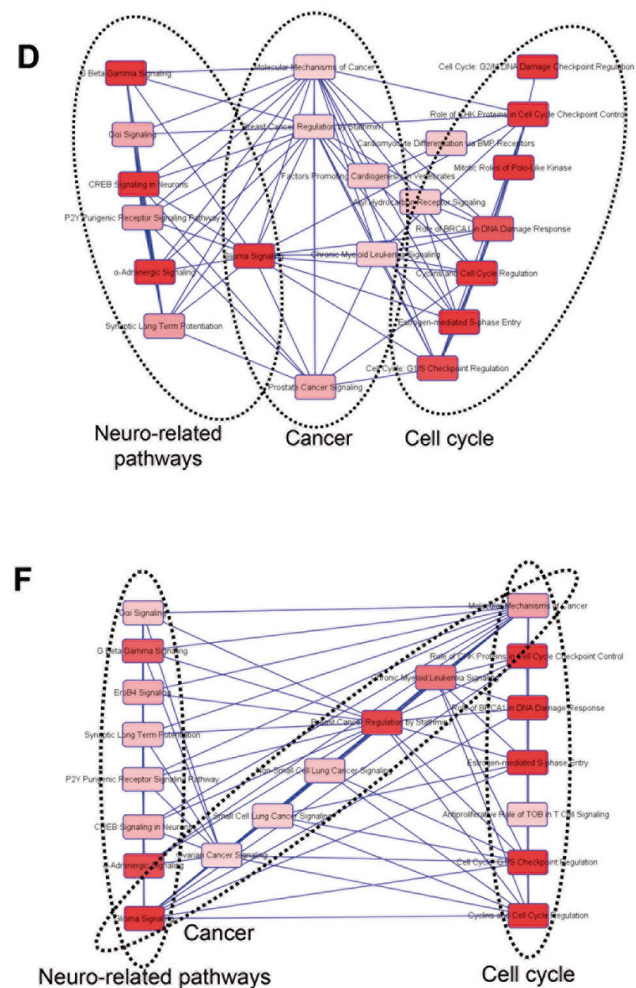

Neuro-related pathways
B

Neuronal development

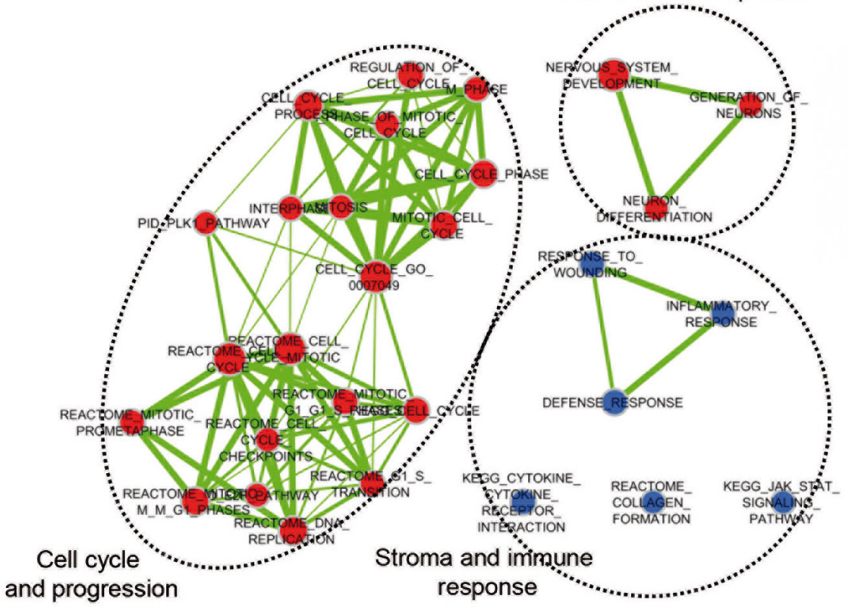

Figure 6: Early NE signature from OPN--TRAMP mice correlates with human NE tumors. A. Hierarchical clustering of early samples obtained from mice free of detectable prostatic lesions (OPT ${ }^{--}$TRAMP 18 wks: light grey; OPN ${ }^{-/}$TRAMP 15 wks: dark grey and TRAMP 18 wks: black). Refer to Suppl. Table 1 and Suppl. Figure3 for detailed description of samples analyzed and flow chart of comparisons. B. Enrichment map showing gene sets significantly enriched in Early-NE compared to Early-ADC according to GSEA. Nodes represent gene sets. Node size is proportional to the number of genes in the gene set. Edges connect overlapping gene sets. Edge thickness indicates the size of the overlap. Red indicates up-regulation, blue indicates down-regulation. C. GSEA plot showing enrichment of genes up-regulated or down-regulated in human NE tumors towards genes over-expressed (left) or down-regulated (right) in OPT-tm compared to T30 mice. D. Canonical pathways, identified by functional analysis with IPA of the core set of genes from human NE samples leading the enrichment in NE OPT-tm samples. E. GSEA plot showing enrichment of genes up-regulated or down-regulated in human NE tumors towards genes over-expressed (left) or down-regulated (right) in Early-NE compared to Early-ADC samples. F. Canonical pathways, identified by functional analysis with IPA of the core set of genes from human NE samples leading the enrichment in Early-NE samples. 
from basal stem-like cells in the TRAMP model [12]. The cytoplasmic staining of p63 (Figure 4D) is in agreement with human $\mathrm{PCa}$, carrying a translocation of p63 from the nucleus to the cytoplasm, an event that has been correlated with increased cell proliferation and dismal prognosis [21].

Clustering analysis performed on gene lists originated by prostate samples from $\mathrm{OPN}^{-/}$TRAMP of 18 wks with US detectable NE tumors and by samples from 30 wks TRAMP with adenocarcinoma, proved the distinct nature of tumors developing early in mice deficient for OPN.

In silico analysis showed that genes promoting cell cycle were most up-regulated in $\mathrm{OPN}^{-/}$TRAMP than TRAMP tumors. Among them CyclinE2 and E2f2 are inducible by estrogens [35], indicating their possible involvement in the development of androgen independent NE tumor [36]. CyclinD1, which promotes cell cycle progression in TRAMP adenocarcinomas [37-39], was down-regulated in NE tumors from $\mathrm{OPN}^{-/}$TRAMP mice. These data are in line with the observation that up to $90 \%$ of human NE xenografts show loss of Cyclin D1 [40]. The similarity between murine and human NE tumors was corroborated by the concordant up-regulation of DDC, a biomarker for human NE PCa [41, 42].

The key genes down-regulated in our signature belong to the TGF $\beta$ pathway and encode for cytoskeletal proteins. TGF $\beta$ mediates the activity of OPN in maintaining hematopoietic stem cells quiescence in the mesenchymal BM niche [43]. Not surprisingly, it might also maintain dormant the prostatic stem cell compartment [26]. The lack of OPN in the prostate stem cell niche may inactivate the TGF $\beta$ pathway and therefore favor the escape from its anti-proliferative control, towards NE tumors development.

In keratinocytes Filamin A (FLNA), a cytoskeletal SMAD-binding protein, binds SMAD2 for effective TFG $\beta$ receptor signaling; accordingly, FLNA-deficient melanoma cells have impaired TGF $\beta$ signaling [25]. In $\mathrm{OPN}^{-/}$TRAMP NE tumors, FLNA was down-regulated at gene and protein levels. SMAD3 gene and protein were also down-regulated although the residual protein was still phosphorylated. SMAD3 is a key intermediated in the TGF $\beta$ pathway [44] and its depletion cannot be overcome by SMAD2 in sustaining TGF $\beta$-mediated cell cycle arrest and growth inhibition [45]. Accordingly, a reduced expression of SMAD3 diminishes the tumorsuppressor function of the TGF $\beta$ pathway in a model of acute T-cell lymphoblastic leukemia [46]. Overall, our data support the conclusion that deregulation of TGF $\beta$ signaling is responsible for increased tumor proliferation and aggressiveness in the OPN ${ }^{-/}$TRAMP model.

Nested class comparison between Early-NE vs Early- $A D C$ tissues identified 184 genes that were all upregulated in prostates from OPN-/-TRAMP at the onset of the still undetectable NE tumors, and that might contain possible biomarkers for early diagnosis.
The validation of $\mathrm{OPN}^{-/}$TRAMP as a reliable model for human NE prostate cancer came from the GSEA analysis on Beltran dataset of PCa patients [27]. Indeed, genes that are up-regulated in human NE prostate cancers were also enriched in our data set from $\mathrm{OPN}^{-/}$TRAMP mice. Common were the genes belonging to canonical pathway related to cancer, neuronal development, cell growth and cell cycle progression.

Modification of the genetic background has been found to change the frequency of NE tumors in TRAMP mice [47], suggesting that polymorphic germline modifier genes may favor NE tumors in this model. Here, using the same C57BL/6 genetic background, we confined to OPN the genetic difference, underscoring a role of OPN in controlling prostate NE tumor outcome. Although this study is the first to demonstrate the role of OPN in prostate tumorigenesis, another SIBLINGs member, namely SPARC, has been shown to favor the occurrence of more aggressive cancers, of undefined histotype in TRAMP mice, if deleted [48]. Altogether these data support the idea that under the same oncogenic driver (SV40 large $\mathrm{T}$ antigen), the ECM composition can influence the phenotype and the aggressiveness of the upcoming tumor. Conversely, in advanced PCa patients both OPN and SPARC overexpression are associated with poor prognosis and metastatic phenotype $[4,32,49]$, implying that the same ECM proteins can exert different functions at different tumor stages.

\section{MATERIALS AND METHODS}

\section{Mice}

TRAMP mice (C57BL/6-tgN (TRAMP)8247Ng) were kindly provided by Dr. Vincenzo Bronte (IRCCS Istituto Oncologico Veneto, Padova, Italy), under agreement with Dr. Norman Michael Greenberg (Fred Hutchinson Cancer Research Center, Seattle, USA). TRAMP mice were maintained heterozygous (TRAMP ${ }^{+-}$) and screened according to [6]. OPN knockout mutant B6.129S6(Cg)-Spp 1 $1^{\text {tmlBlh }} / \mathrm{J}_{\left(\mathrm{OPN}^{-/-}\right)}$ mice were purchased from Jackson Laboratories and intercrossed to TRAMP mice, in order to obtain congenic B6.tgN (TRAMP)8247Ng Spp $1<\operatorname{tm} 1 B l h>/ J$ $\left(\mathrm{OPN}^{-/-}\right.$TRAMP). Female mice heterozygous for Tag $\left(\mathrm{TRAMP}^{+-}\right.$) and $\mathrm{OPN}^{-/}$were bred with male $\mathrm{OPN}^{--}$ mice to obtain experimental $\mathrm{OPN}^{-/} \mathrm{TRAMP}^{+/}$mice, which were genotyped for Tag expression [6]. Mice were maintained under pathogen-free conditions at the animal facility of Fondazione IRCCS Istituto Nazionale dei Tumori. Animal experiments were authorized by the Institute Ethical Committee and performed in accordance to institutional guidelines and national law (D.lgs 26/2014). Prostate tumor growth was echo-graphically monitored using a Vevo 770 microultrasound imaging system (Visualsonics Inc., Toronto, 
Canada) as described [50]. Castration was performed after anesthesia $(100 \mathrm{mg} / \mathrm{kg}$ Ketamine, $16 \mathrm{mg} / \mathrm{kg}$ Xylazine) as described [51].

\section{Histology, immunohistochemistry}

Prostates were fixed in formalin and embedded in paraffin. $5 \mu \mathrm{M}$ sections were stained with MayerHematoxylin and Eosin (H\&E). Alternatively, after re-hydratation and antigen retrieval, immunohistochemistry was performed using the streptavidin-biotin-peroxidase complex method, and 3,3'-Diaminobenzidine tetrahydrochloride as chromogenic substrate. Primary antibodies were: Ki67 (TEC-3, Dako, Glostrup Denmark), N-cadherin (Abcam, Cambridge, MA, USA), Laminin (Biodesign, Memphis, TN, USA), Androgen Receptor (Merck Millipore, Milano, Italy) Synaptophysin (Abcam,), SV40 Tag (clone pAb101, BD Biosciences, Buccinasco Italy), OPN (AbCam). Slides were analyzed under a Leica DM2000 optical microscope equipped with a Leica DFC320 digital camera (Leica Microsystems, Milan, Italy).

\section{Immunofluorescence}

Sections were incubated with primary antibody anti $\mathrm{Ki} 67 \mathrm{o} / \mathrm{n}$ at $4^{\circ} \mathrm{C}$, then washed in PBS and incubated for $1 \mathrm{~h}$ with an Alexa-488 anti-rabbit antibody. Slides were then incubated with anti CK8 or anti p63 antibodies (Abcam) for $1 \mathrm{~h}$, washed and further incubated with Alexa-568 anti-mouse antibody. Sections were counter stained with DAPI and analyzed with a Microradiance 2000 (BioRad Laboratories, Segrate, Italy) confocal microscope equipped with $\mathrm{Ar}(488 \mathrm{~nm}), \mathrm{HeNe}(543 \mathrm{~nm})$ and red laser diode $(638 \mathrm{~nm})$ lasers. Confocal images $(512 \times 512$ pixels $)$ were obtained using a x200, 0.5 NA Plan Fluor DIC or x600 1.4 NA oil immersion lens and analyzed using ImagePro 7.0.1 software.

\section{RT-qPCR}

Prostates were lysed with TRIzol (Invitrogen, Life Technologies, Monza, Italy) and RNA was purified by phenol/chloroform extraction followed by loading onto RNeasy MINI kit (Qiagen, Milan, Italy). On-column DNAse treatment was performed. RNA purity and yield was assessed using NanoDrop ND-100 Spectrophotometer (NanoDrop Technologies, Wilmington, DE).

RNA was Reverse Transcribed using High Capacity cDNA Reverse Transcription Kit (Applied Biosystems). RT-qPCR reaction was prepared using TaqMan (R) Fast Universal PCR Master Mix and run on a 7900 HT Fast Real-time PCR System (Applied Biosystems, Life Technologies, Monza, Italy) as described previously [52]. The following TaqMan(R) probes were used: Gapdh (Mm99999915_g1), Ccne2 (Mm00438077_m1), Ccnd1
(Mm00432359_m1), E2f2 (Mm00624964_m1), Ddc (Mm00516688_m1), Syp (Mm00436850_m1). Expression values were normalized to internal control (Gapdh) and to control sample (TRAMP prostate) calculating the $\Delta \Delta \mathrm{CT}$.

\section{Western blot}

Ten sections of $10 \mathrm{~mm}$ from frozen samples of TRAMP or OPN ${ }^{-/}$TRAMP tumors were lysed, run on a $4-12 \%$ Bis-Tris Gel (Invitrogen) and transferred on a NC membrane (Amersham, GE Healthcare, Milano, Italy). Primary antibodies against Smad3, Smad2, phospho Smad2, phospho Smad3, Filamin, DDC and Syp were from Cell Signaling Technology, against $\beta$-actin from SIGMA Aldrich. Secondary HRP antibodies were goat anti-rabbit and rabbit anti-goat (Invitrogen). Densitometric analysis was performed using the ImageJ $1.48 \mathrm{v}$ software (http://imagej.nih.gov/ij).

\section{Gene expression profiling}

We collected prostates from 18 wks old TRAMP mice $(\mathrm{T} 18, n=4)$, with null or minimal disease, from $30 \mathrm{wks}$ old TRAMP mice (T30, $n=4)$ in which adenocarcinoma was palpable and detectable by US, from $\mathrm{OPN}^{-1-}$ TRAMP mice of 15 or 18 wks of age (OPT15, $n=5$ and OPT18, $n$ $=9$, respectively) without any detectable lesion and from 18 wks old $\mathrm{OPN}^{--}$TRAMP mice with detectable NE tumor mass (OPT18tm, $n=3$ ). A detailed description of samples used for microarray comparison is in Suppl. Table 1, and a detailed flow chart depicting how samples were compared is in Suppl. Figure 3

RNA was isolated using the guanidinium thiocyanate/cesium chloride gradient method [53]. RNA concentrations were measured with the NanoDrop ND-100 Spectrophotometer (NanoDrop Technologies) while RNA quality was assessed with the Agilent 2100 Bioanalyzer (Agilent Technologies, Palo Alto, CA, USA) using the RNA 6000 Nano kit (Agilent Technologies). The mean RIN value was $8.028(\mathrm{SD}=0.65)$. RNA samples were processed for microarray hybridization by the Functional Genomics core facility at Fondazione IRCCS Istituto Nazionale dei Tumori, Milan. Briefly, 800 ng of total RNA was reverse transcribed, labeled with biotin and amplified overnight (14 hours) using the Illumina RNA TotalPrep Amplification kit (Ambion, Life Technologies, Grand Island, NY, USA) according to manufacturer's protocol. One $\mu \mathrm{g}$ of the biotinylated cRNA sample was mixed with the Hyb E1 hybridizatioin buffer containing $37.5 \%(\mathrm{w} / \mathrm{w})$ formamide and then hybridized to array MouseRef- 8 v2.0 Expression BeadChip (Illumina, Inc., San Diego, CA, USA) at $58^{\circ} \mathrm{C}$ overnight (18 hours). Array chips were washed with manufacturer's E1BC solution, stained with $1 \mu \mathrm{g} / \mathrm{ml} \mathrm{Cy} 3$-streptavidine (Amersham Biosciences; GE Healthcare, Piscataway, NJ, USA) and scanned with Illumina BeadArray ${ }^{\mathrm{TM}}$ Reader. 


\section{Microrarray data pre-processing}

Raw expression data were collected from scanned images using Illumina BeadStudio v3.3.8 and processed using the lumi package from Bioconductor [54]. Quality control was performed on raw and processed data by evaluation of array intensity distributions, distances between arrays, and by principal component analysis for the identification of possible outliers. All samples passed quality-control procedures. Raw data were $\log _{2}-$ transformed, normalized with robust spline normalization and filtered, keeping only the probes with a detection $p$-value $<0.01$ in at least one sample. Among probes mapping on the same gene the most detected one was chosen. All array data have been deposited in NCBI's Gene Expression Omnibus and are accessible through GEO Series accession number GSE69903.

\section{Microarray data analysis}

Differentially expressed genes between classes were identified using the limma package [55]. $P$-values were corrected for multiple testing using the BenjaminiHochberg false discovery rate method. An FDR $<0.05$ and an absolute fold change $\geq 2$ were used as criteria for selection of differentially expressed genes. Agglomerative hierarchical clustering was performed using average linkage and 1-Pearson's correlation coefficient as distance measure. Gene Set Enrichment Analysis (GSEA [56]) was applied to identify biological processes enriched in the different groups. Gene sets were retrieved from the $\mathrm{c} 2$ canonical pathways and c5 biological process collections from the MSigDB database (http://www.broadinstitute. org/gsea/msigdb/index.jsp). Significantly enriched gene sets $(p<0.001$ and $\mathrm{FDR}<0.05)$ were visualized using Cytoscape v2.8.3 and the Enrichment Map plugin [57]. Functional analyses of gene lists were generated through the use of IPA(QIAGEN, www.qiagen.com/ingenuity).

\section{Statistical analysis}

We used GraphPad Prism software (GraphPad Software, La Jolla, CA, USA). Student's $t$-test was used for comparison of quantitative variables. Association between categorical variables was carried out using Fisher's exact test. Log-Rank test was applied for survival curves. All statistical tests were two-sided and a $p$-value $<0.05$ was considered significant.

\section{ACKNOWLEDGMENTS}

We thank P. Casalini from Istituto Nazionale Tumori di Milano for confocal microscopy analysis.

\section{CONFLICTS OF INTEREST}

No potential conflicts of interest were disclosed.

\section{GRANT SUPPORT}

This work was supported by grants from Fondazione Italo Monzino (to MPC), Associazione Italiana per la Ricerca sul Cancro (I.G. n 14194 to MPC and I.G. n.13134 to EDC), and the "Umberto Veronesi" Foundation for the Progress of Sciences (to EDC).

\section{Editorial note}

This paper has been accepted based in part on peerreview conducted by another journal and the authors' response and revisions as well as expedited peer-review in Oncotarget.

\section{REFERENCES}

1. Siegel R, Ma J, Zou Z and Jemal A. Cancer statistics, 2014. CA Cancer J Clin. 2014; 64:9-29.

2. Chiodoni C, Colombo MP and Sangaletti S. Matricellular proteins: from homeostasis to inflammation, cancer, and metastasis. Cancer Metastasis Rev. 2010; 29:295-307.

3. Grassinger J, Haylock DN, Storan MJ, Haines GO, Williams B, Whitty GA, Vinson AR, Be CL, Li S, Sorensen ES, Tam PP, Denhardt DT, Sheppard D, Choong PF and Nilsson SK. Thrombin-cleaved osteopontin regulates hemopoietic stem and progenitor cell functions through interactions with alpha9beta1 and alpha4beta1 integrins. Blood. 2009; 114:49-59.

4. Castellano G, Malaponte G, Mazzarino MC, Figini M, Marchese F, Gangemi P, Travali S, Stivala F, Canevari S and Libra M. Activation of the osteopontin/matrix metalloproteinase-9 pathway correlates with prostate cancer progression. Clin Cancer Res. 2008; 14:7470-7480.

5. Thalmann GN, Sikes RA, Devoll RE, Kiefer JA, Markwalder R, Klima I, Farach-Carson CM, Studer UE and Chung LW. Osteopontin: possible role in prostate cancer progression. Clin Cancer Res. 1999; 5:2271-2277.

6. Greenberg NM, DeMayo F, Finegold MJ, Medina D, Tilley WD, Aspinall JO, Cunha GR, Donjacour AA, Matusik RJ and Rosen JM. Prostate cancer in a transgenic mouse. Proc Natl Acad Sci U S A. 1995; 92:3439-3443.

7. Shappell SB, Thomas GV, Roberts RL, Herbert R, Ittmann MM, Rubin MA, Humphrey PA, Sundberg JP, Rozengurt N, Barrios R, Ward JM and Cardiff RD. Prostate pathology of genetically engineered mice: definitions and classification. The consensus report from the Bar Harbor meeting of the Mouse Models of Human Cancer Consortium Prostate Pathology Committee. Cancer Res. 2004; 64:2270-2305.

8. di Sant'Agnese PA. Neuroendocrine differentiation in prostatic carcinoma: an update on recent developments. Ann Oncol. 2001; 12:S135-140.

9. Terry $\mathrm{S}$ and Beltran H. The many faces of neuroendocrine differentiation in prostate cancer progression. Front Oncol. 2014; 4:60. 
10. Bostwick DG, Dousa MK, Crawford BG and Wollan PC. Neuroendocrine differentiation in prostatic intraepithelial neoplasia and adenocarcinoma. Am J Surg Pathol. 1994; 18:1240-1246.

11. Komiya A, Suzuki H, Imamoto T, Kamiya N, Nihei N, Naya Y, Ichikawa T and Fuse H. Neuroendocrine differentiation in the progression of prostate cancer. International journal of urology : official journal of the Japanese Urological Association. 2009; 16:37-44.

12. Chiaverotti T, Couto SS, Donjacour A, Mao JH, Nagase H, Cardiff RD, Cunha GR and Balmain A. Dissociation of epithelial and neuroendocrine carcinoma lineages in the transgenic adenocarcinoma of mouse prostate model of prostate cancer. Am J Pathol. 2008; 172:236-246.

13. Gingrich JR, Barrios RJ, Kattan MW, Nahm HS, Finegold MJ and Greenberg NM. Androgen-independent prostate cancer progression in the TRAMP model. Cancer Res. 1997; 57:4687-4691.

14. Zhang ZX, Xu QQ, Huang XB, Zhu JC and Wang XF. Early and delayed castrations confer a similar survival advantage in TRAMP mice. Asian J Androl. 2009; 11:291-297.

15. Greenberg NM, DeMayo FJ, Sheppard PC, Barrios R, Lebovitz R, Finegold M, Angelopoulou R, Dodd JG, Duckworth ML, Rosen JM et al. The rat probasin gene promoter directs hormonally and developmentally regulated expression of a heterologous gene specifically to the prostate in transgenic mice. Mol Endocrinol. 1994; 8:230-239.

16. Bono AV, Montironi R, Pannellini T, Sasso F, Mirone V, Musiani $\mathrm{P}$ and Iezzi M. Effects of castration on the development of prostate adenocarcinoma from its precursor HGPIN and on the occurrence of androgen-independent, poorly differentiated carcinoma in TRAMP mice. Prostate Cancer Prostatic Dis. 2008; 11:377-383.

17. Mazzoleni S, Jachetti E, Morosini S, Grioni M, Piras IS, Pala M, Bulfone A, Freschi M, Bellone M and Galli R. Gene signatures distinguish stage-specific prostate cancer stem cells isolated from transgenic adenocarcinoma of the mouse prostate lesions and predict the malignancy of human tumors. Stem Cells Transl Med. 2013; 2:678-689.

18. Huss WJ, Gray DR, Tavakoli K, Marmillion ME, Durham LE, Johnson MA, Greenberg NM and Smith GJ. Origin of androgen-insensitive poorly differentiated tumors in the transgenic adenocarcinoma of mouse prostate model. Neoplasia. 2007; 9:938-950.

19. Davis LD, Zhang W, Merseburger A, Young D, Xu L, Rhim JS, Moul JW, Srivastava S and Sesterhenn IA. p63 expression profile in normal and malignant prostate epithelial cells. Anticancer Res. 2002; 22:3819-3825.

20. Ferronika P, Triningsih FX, Ghozali A, Moeljono A, Rahmayanti S, Shadrina AN, Naim AE, Wudexi I, Arnurisa AM, Nanwani ST and Harijadi A. p63 cytoplasmic aberrance is associated with high prostate cancer stem cell expression. Asian Pac J Cancer Prev. 2012; 13:1943-1948.
21. Dhillon PK, Barry M, Stampfer MJ, Perner S, Fiorentino M, Fornari A, Ma J, Fleet J, Kurth T, Rubin MA and Mucci LA. Aberrant cytoplasmic expression of p63 and prostate cancer mortality. Cancer Epidemiol Biomarkers Prev. 2009; 18:595-600.

22. Miki J and Rhim JS. Prostate cell cultures as in vitro models for the study of normal stem cells and cancer stem cells. Prostate Cancer Prostatic Dis. 2008; 11:32-39.

23. Shukla S, Maclennan GT, Marengo SR, Resnick MI and Gupta S. Constitutive activation of P I3 K-Akt and NF-kappaB during prostate cancer progression in autochthonous transgenic mouse model. Prostate. 2005; 64:224-239.

24. Kumar AP, Bhaskaran S, Ganapathy M, Crosby K, Davis MD, Kochunov P, Schoolfield J, Yeh IT, Troyer DA and Ghosh R. Akt/cAMP-responsive element binding protein/cyclin D1 network: a novel target for prostate cancer inhibition in transgenic adenocarcinoma of mouse prostate model mediated by Nexrutine, a Phellodendron amurense bark extract. Clin Cancer Res. 2007; 13:2784-2794.

25. Sasaki A, Masuda Y, Ohta Y, Ikeda K and Watanabe K. Filamin associates with Smads and regulates transforming growth factor-beta signaling. J Biol Chem. 2001; 276:17871-17877.

26. Salm SN, Burger PE, Coetzee S, Goto K, Moscatelli D and Wilson EL. TGF-\{beta\} maintains dormancy of prostatic stem cells in the proximal region of ducts. J Cell Biol. 2005; 170:81-90.

27. Beltran H, Rickman DS, Park K, Chae SS, Sboner A, MacDonald TY, Wang Y, Sheikh KL, Terry S, Tagawa ST, Dhir R, Nelson JB, de la Taille A, et al. Molecular characterization of neuroendocrine prostate cancer and identification of new drug targets. Cancer Discov. 2011; 1:487-495.

28. Dvorak HF. Tumors: wounds that do not heal. Similarities between tumor stroma generation and wound healing. $\mathrm{N}$ Engl J Med. 1986; 315:1650-1659.

29. Sung SY and Chung LW. Prostate tumor-stroma interaction: molecular mechanisms and opportunities for therapeutic targeting. Differentiation. 2002; 70:506-521.

30. Brown LF, Papadopoulos-Sergiou A, Berse B, Manseau EJ, Tognazzi K, Perruzzi CA, Dvorak HF and Senger DR. Osteopontin expression and distribution in human carcinomas. Am J Pathol. 1994; 145:610-623.

31. Thoms JW, Dal Pra A, Anborgh PH, Christensen E, Fleshner N, Menard C, Chadwick K, Milosevic M, Catton C, Pintilie M, Chambers AF and Bristow RG. Plasma osteopontin as a biomarker of prostate cancer aggression: relationship to risk category and treatment response. $\mathrm{Br} \mathrm{J}$ Cancer. 2012; 107:840-846.

32. Chaplet M, Waltregny D, Detry C, Fisher LW, Castronovo $\mathrm{V}$ and Bellahcene A. Expression of 
dentin sialophosphoprotein in human prostate cancer and its correlation with tumor aggressiveness. Int J Cancer. 2006; 118:850-856.

33. Bandopadhyay M, Bulbule A, Butti R, Chakraborty G, Ghorpade P, Ghosh P, Gorain M, Kale S, Kumar D, Kumar S, Totakura KV, Roy G, Sharma P, et al. Osteopontin as a therapeutic target for cancer. Expert Opin Ther Targets. 2014; 18:883-895.

34. Johnson MA, Iversen P, Schwier P, Corn AL, Sandusky G, Graff J and Neubauer BL. Castration triggers growth of previously static androgen-independent lesions in the transgenic adenocarcinoma of the mouse prostate (TRAMP) model. Prostate. 2005; 62:322-338.

35. Caldon CE, Sergio CM, Schutte J, Boersma MN, Sutherland RL, Carroll JS and Musgrove EA. Estrogen regulation of cyclin E2 requires cyclin D1 but not c-Myc. Mol Cell Biol. 2009; 29:4623-4639.

36. Ellem SJ and Risbridger GP. Treating prostate cancer: a rationale for targeting local oestrogens. Nat Rev Cancer. 2007; 7:621-627.

37. Shukla S, Bhaskaran N, Babcook MA, Fu P, Maclennan GT and Gupta $\mathrm{S}$. Apigenin inhibits prostate cancer progression in TRAMP mice via targeting PI3K/Akt/FoxO pathway. Carcinogenesis. 2014; 35:452-460.

38. Khor TO, Yu S, Barve A, Hao X, Hong JL, Lin W, Foster B, Huang MT, Newmark HL and Kong AN. Dietary feeding of dibenzoylmethane inhibits prostate cancer in transgenic adenocarcinoma of the mouse prostate model. Cancer Res. 2009; 69:7096-7102.

39. Shukla S, MacLennan GT, Flask CA, Fu P, Mishra A, Resnick MI and Gupta S. Blockade of beta-catenin signaling by plant flavonoid apigenin suppresses prostate carcinogenesis in TRAMP mice. Cancer Res. 2007; 67:6925-6935.

40. Tzelepi V, Zhang J, Lu JF, Kleb B, Wu G, Wan X, Hoang A, Efstathiou E, Sircar K, Navone NM, Troncoso P, Liang S, Logothetis CJ, Maity SN and Aparicio AM. Modeling a lethal prostate cancer variant with small-cell carcinoma features. Clin Cancer Res. 2012; 18:666-677.

41. Margiotti K, Wafa LA, Cheng H, Novelli G, Nelson CC and Rennie PS. Androgen-regulated genes differentially modulated by the androgen receptor coactivator L-dopa decarboxylase in human prostate cancer cells. Mol Cancer. 2007; 6:38.

42. Wafa LA, Palmer J, Fazli L, Hurtado-Coll A, Bell RH, Nelson CC, Gleave ME, Cox ME and Rennie PS. Comprehensive expression analysis of L-dopa decarboxylase and established neuroendocrine markers in neoadjuvant hormone-treated versus varying Gleason grade prostate tumors. Hum Pathol. 2007; 38:161-170.

43. Stier S, Ko Y, Forkert R, Lutz C, Neuhaus T, Grunewald E, Cheng T, Dombkowski D, Calvi LM, Rittling SR and
Scadden DT. Osteopontin is a hematopoietic stem cell niche component that negatively regulates stem cell pool size. J Exp Med. 2005; 201:1781-1791.

44. Massague J. TGFbeta in Cancer. Cell. 2008; 134:215-230.

45. Kim SG, Kim HA, Jong HS, Park JH, Kim NK, Hong SH, Kim TY and Bang YJ. The endogenous ratio of Smad2 and Smad3 influences the cytostatic function of Smad3. Mol Biol Cell. 2005; 16:4672-4683.

46. Wolfraim LA, Fernandez TM, Mamura M, Fuller WL, Kumar R, Cole DE, Byfield S, Felici A, Flanders KC, Walz TM, Roberts AB, Aplan PD, Balis FM and Letterio JJ. Loss of Smad3 in acute T-cell lymphoblastic leukemia. N Engl J Med. 2004; 351:552-559.

47. Patel SJ, Molinolo AA, Gutkind S and Crawford NP. Germline genetic variation modulates tumor progression and metastasis in a mouse model of neuroendocrine prostate carcinoma. PLoS One. 2013; 8:e61848.

48. Said N, Frierson HF, Jr., Chernauskas D, Conaway M, Motamed K and Theodorescu D. The role of SPARC in the TRAMP model of prostate carcinogenesis and progression. Oncogene. 2009; 28:3487-3498.

49. Derosa CA, Furusato B, Shaheduzzaman S, Srikantan V, Wang Z, Chen Y, Seifert M, Ravindranath L, Young D, Nau M, Dobi A, Werner T, McLeod DG, et al. Elevated osteonectin/SPARC expression in primary prostate cancer predicts metastatic progression. Prostate Cancer Prostatic Dis. 2012; 15:150-156.

50. Wirtzfeld LA, Wu G, Bygrave M, Yamasaki Y, Sakai H, Moussa M, Izawa JI, Downey DB, Greenberg NM, Fenster A, Xuan JW and Lacefield JC. A new three-dimensional ultrasound microimaging technology for preclinical studies using a transgenic prostate cancer mouse model. Cancer Res. 2005; 65:6337-6345.

51. Li S, Hu MG, Sun Y, Yoshioka N, Ibaragi S, Sheng J, Sun G, Kishimoto K and Hu GF. Angiogenin mediates androgen-stimulated prostate cancer growth and enables castration resistance. Mol Cancer Res. 2013; 11:1203-1214.

52. Sangaletti S, Tripodo C, Sandri S, Torselli I, Vitali C, Ratti C, Botti L, Burocchi A, Porcasi R, Tomirotti A, Colombo MP and Chiodoni C. Osteopontin shapes immunosuppression in the metastatic niche. Cancer Res. 2014; 74:4706-4719.

53. Chirgwin JM, Przybyla AE, MacDonald RJ and Rutter WJ. Isolation of biologically active ribonucleic acid from sources enriched in ribonuclease. Biochemistry. 1979; 18:5294-5299.

54. Du P, Kibbe WA and Lin SM. lumi: a pipeline for processing Illumina microarray. Bioinformatics. 2008; 24:1547-1548.

55. Smyth GK. Linear models and empirical bayes methods for assessing differential expression in microarray experiments. Stat Appl Genet Mol Biol. 2004; 3:Article3. 
56. Subramanian A, Tamayo P, Mootha VK, Mukherjee S, Ebert BL, Gillette MA, Paulovich A, Pomeroy SL, Golub TR, Lander ES and Mesirov JP. Gene set enrichment analysis: a knowledge-based approach for interpreting genomewide expression profiles. Proc Natl Acad Sci U S A. 2005; 102:15545-15550.
57. Merico D, Isserlin R, Stueker O, Emili A and Bader GD. Enrichment map: a network-based method for gene-set enrichment visualization and interpretation. PLoS One. 2010; 5:e13984. 